\title{
Brain Cancer Stem Cells in Adults and Children: Cell Biology and Therapeutic Implications
}

\author{
Tamara J. Abou-Antoun ${ }^{1}$ • James S. Hale ${ }^{2}$ Justin D. Lathia ${ }^{2,3,4}$. \\ Stephen M. Dombrowski ${ }^{5}$
}

Published online: 3 April 2017

(C) The American Society for Experimental NeuroTherapeutics, Inc. 2017

\begin{abstract}
Brain tumors represent some of the most malignant cancers in both children and adults. Current treatment options target the majority of tumor cells but do not adequately target self-renewing cancer stem cells (CSCs). CSCs have been reported to resist the most aggressive radiation and chemotherapies, and give rise to recurrent, treatmentresistant secondary malignancies. With advancing technologies, we now have a better understanding of the genetic, epigenetic and molecular signatures and microenvironmental influences which are useful in distinguishing between distinctly different tumor subtypes. As a result, efforts are now underway to identify and target CSCs within various tumor subtypes based on this foundation. This review discusses progress in CSC biology as it relates to targeted therapies which may be uniquely different between pediatric and adult brain tumors. Studies to date suggest that pediatric brain tumors may benefit more from genetic and epigenetic targeted therapies, while combination treatments aimed
\end{abstract}

Stephen M. Dombrowski

dombros@ccf.org

1 School of Pharmacy, Department of Pharmaceutical Sciences, Lebanese American University, Byblos, Lebanon

2 Department of Cellular and Molecular Medicine, Lerner Research Institute, Cleveland Clinic, Cleveland, OH, USA

3 Department of Molecular Medicine, Cleveland Clinic Lerner College of Medicine at Case, Western Reserve University, Cleveland, $\mathrm{OH}$, USA

4 Case Comprehensive Cancer Center, Cleveland, OH, USA

5 Department of Neurological Surgery, Section of Pediatric Neurosurgical Oncology, Neurological Institute, Cleveland Clinic, Cleveland, OH, USA specifically at multiple molecular pathways may be more effective in treating adult brain tumors which seem to have a greater propensity towards microenvironmental interactions. Ultimately, CSC targeting approaches in combination with current clinical therapies have the potential to be more effective owing to their ability to compromise CSCs maintenance and the mechanisms which underlie their highly aggressive and deadly nature.

Keywords Cancer stem cells · Childhood brain tumors . Glioblastoma $\cdot$ Epigenetics $\cdot$ Microenvironment $\cdot$ Therapeutic implications

\section{Introduction}

Brain tumors are a complex collection of diseases with an anticipated 23,770 cases per year and an associated 16,050 deaths per year [1].These malignancies account for the leading cause of cancer death in children. Among the most malignant and aggressive forms of these tumors are glioblastoma multiforme (GBM; World Health Organization grade IV astrocytoma), characterized by increased mitotic index, necrosis and vascular proliferation [2]. GBM survival rates have remained largely unchanged since the 1960s, with a median survival time of 12-18 months [3]. Current treatment regimens are palliative in nature and involve surgical resection, ionizing radiation, and chemotherapy, highlighting the need for more effective therapies that exploit the unique biology of solid tumors and their microenvironment [4].

Cellular heterogeneity has long been appreciated as a hallmark in these tumors, similar to what has been observed in the normal brain. Stem cell populations reside in many tissues and are responsible for tissue development and homeostasis, giving rise to diverse cell types organized in defined cellular 
hierarchies. Traditionally, stem cells have been defined by an ability to self-renew and differentiate along multiple lineages [5]. Within the brain, neural stem/progenitor cells (NSPCs) give rise to neurons and glia [6] via the generation of intermediate progenitor cells that have a more restricted differentiation potential and serve as a transit-amplifying population between NSPCs and their terminal progeny. Two main stem reservoirs or neurogenic zones have been identified in the adult brain: 1) the subventricular zone adjacent to the lateral ventricle, and 2) the subgranular zone of the dentate gyrus in the hippocampus [7]. Within these distinct anatomical locations, there is interaction of NSPCs with other cell types, including endothelial cells, which regulate NSPC behavior [8]. These zones are crucial to the maintenance of NSPCs and highlight the potential importance of microenvironmental regulation in the stem-cell state that is also likely important in the context of brain tumors.

\section{Cancer Stem Cells}

Within a tumor lays a subset of self-renewing, multi-potent cancer stem cells (CSCs) that phenotypically and functionally resemble normal stem cells and drive tumor growth and recurrence. The CSC hypothesis has been influenced by the desire to provide a model for the development and maintenance of cellular heterogeneity and inspired by the long-standing observations that cancer has many similarities with development, which has compared a tumor to an aberrantly developed organ. By leveraging in vitro functional aspects used to define and enrich NSPCs [9], and the ability to form clonal, freefloating spheres in culture, CSCs were characterized directly from patient-derived tumors in multiple cancer types, including breast [10], colon [11], brain [12], and ovarian [13]. The CSC hypothesis provides an additional paradigm for the development of cellular heterogeneity and identifies a population of cells that continue to persist, despite aggressive therapies. This model does not take into account the multiple layers of oncogenic mutations necessary to initiate tumor or clonal relationships that may persist during tumor growth. Furthermore, the CSC hypothesis provides a model for potential lineage relationships between tumor cells but cannot definitively explain the cell(s) of origin that initiate a tumor [14].

CSC studies have relied on several functional characteristics to assess differences with non-stem tumor cell progeny, including sustained self-renewal, persistent proliferation, differentiation potential, and an increased ability to initiate tumors (Fig. 1). Compared with CSCs, the non-stem tumor cells are generally more sensitive to conventional therapy and are unable to recapitulate the heterogeneity of the original tumor. Associated characteristics such as low frequency within a tumor, ability to differentiate along multiple lineages, and stem cell marker expression have been observed, but, importantly, these are not functional properties [4]. To enrich brain tumor
CSCs for functional studies, multiple cell-surface marker strategies have been used, including CD133 [15], CD49f [16], CD36 [17], A2B5 [18], CD44 [19], L1CAM [20], and epidermal growth factor receptor (EGFR) [21], found mostly in adult GBM. The expression of these cell-surface markers vary within patient-derived tumors and xenograft models, and some of these markers have been demonstrated to also be a therapeutic target as reduction in expression has resulted in decreased self-renewal. Several transcription factors have also been identified to play pivotal functional roles in the CSC subpopulations, including BMI1 [22], Olig2 [23], and SOX2 [24]. In addition to altered protein expression, unique epigenetic patterns in the form of altered DNA methylation signatures, which underlie the altered protein expression, have been identified in adult GBM [25].

The first CSCs to be identified in a childhood cancer were acute myeloid leukemia stem cells [26], which were found to express the hematopoietic stem marker CD34, but not the lymphocyte differentiation marker CD38 [27]. Since this observation, multiple pediatric brain tumors have been reported to harbor CSCs, including medulloblastomas [28] and highgrade gliomas (HGGs) [29]. The identification of pediatric brain CSCs follows the same rationale as in adults; most reports have isolated CSCs from within bulk tumors using the previously reported stem markers and verified their capacity to self-renew, differentiate, and recapitulate the tumor of origin. Along with expression of adult brain tumor CSC markers (including CD133, SOX2, musashi-1, BMI1), pediatric brain tumor CSCs also express elevated maternal embryonic leucine zipper kinase and phosphoserine phosphatase expression [15]. In addition, mouse models have been developed that can distinguish pediatric brain tumor CSCs based on the expression of CD15 [30], Nestin [65], or Sox2 [31].

Another important property of CSC is resistance to many therapeutic approaches, including radiation and chemotherapy. These therapeutic approaches have increased efficacy towards non-stem tumor cells but do not effectively target CSCs; CSCs are often enriched in treated tumors. Current therapies can also impact the tumor microenvironment and generate stresses that can induce the stem cell state, including alterations in $\mathrm{pH}$, oxygen content, or nutrient supply (Fig. 2). While CSCs have been identified in pediatric and adult brain tumors, it is important to highlight that these tumors are considerably different and therefore the CSC populations within them may differ from each other and may represent distinct targets that may be utilized therapeutically for better clinical outcomes (Table 1).

\section{CSC Therapeutic Resistance}

CSCs are frequently refractory to therapeutic intervention and, as such, are able to repropagate the tumor mass following various treatments $[32,33]$. One explanation may be that 
Fig. 1 Cancer stem cells

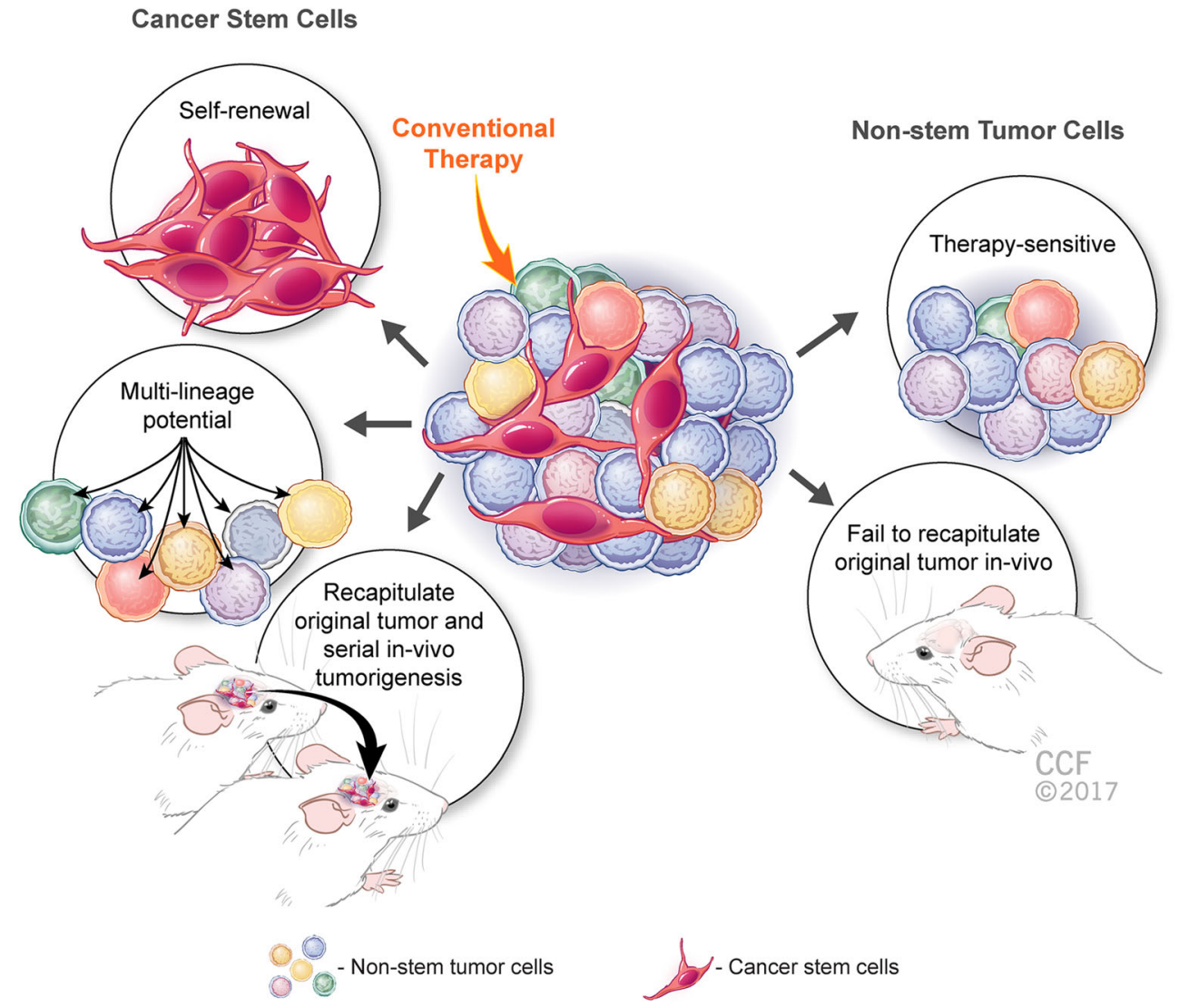

following treatment, radiation- and chemoresistant populations of CSCs have been selected and enriched leading to therapeutic resistance and tumor recurrence. Ionizing radiation is delivered in wave form (i.e., x-ray or gamma ray) and
Fig. 2 Plasticity and therapeutic implications. $\mathrm{CSC}=$ cancer stem cell

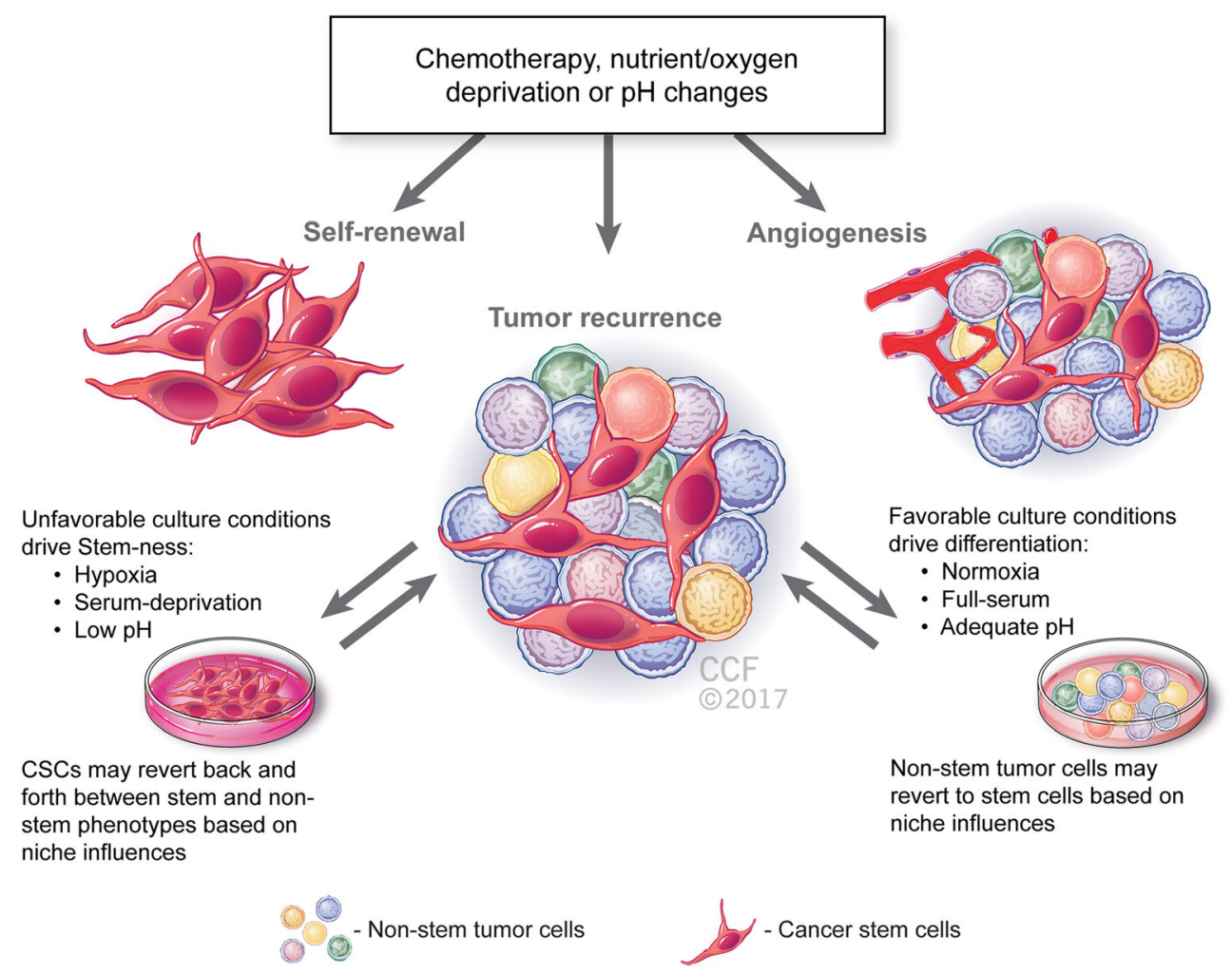


Table 1 Brain cancer stem cell characterization in pediatric and adult patients

\begin{tabular}{|c|c|c|c|c|}
\hline Cancer type & Stem cell distinction & Gene aberrations & Epigenetic aberrations & Molecular drivers \\
\hline Pediatric brain cancer stem cells & $\begin{array}{l}\text { CD133 } \\
\text { CD49f } \\
\text { CD140a } \\
\text { Nestin } \\
\text { CD15 } \\
\text { SOX2 }\end{array}$ & $\begin{array}{l}\text { ACVR1 mutation } \\
\text { ERBB1 amplification } \\
A T R X \\
H 3 F 3 A \text { mutation } \\
D A X X \text { mutation } \\
T P 53 \\
N F-1 \\
B R A F \\
K R A S \\
\text { PDGFRA }\end{array}$ & $\begin{array}{l}\text { H3K27M } \\
\text { BMI1 } \\
\text { FOXG1 } \\
\text { SOX2 } \\
\text { Musashi-1 } \\
\text { ATRX } \\
\text { BMP1 } \\
\text { EZH2 }\end{array}$ & $\begin{array}{l}\text { MYCN } \\
\text { Wnt/ } \beta \text {-catenin } \\
\text { Sonic hedgehog } \\
\text { NOTCH } \\
\text { PI3K/Akt/mTOR }\end{array}$ \\
\hline Adult brain cancer stem cells & $\begin{array}{l}\text { CD133 } \\
\text { CD49f } \\
\text { EGFR } \\
\text { L1CAM } \\
\text { CD44 } \\
\text { CD36 } \\
\text { A2B5 }\end{array}$ & $\begin{array}{l}\text { Amplifications or gain-of-function } \\
\text { mutations in: } \\
E G F R \\
P D G F R A / B \\
H D M 2 \\
P I K 3 C A \text {, and PIK3R1 } \\
\text { Mutations or deletions of the } \\
\text { tumor suppressors: } \\
\text { PTEN } \\
\text { TP53 } \\
C D K N 2 A \\
N F 1 \\
\text { ATRX and } R B 1 \\
\text { Mutations with favorable } \\
\text { outcomes: } \\
\text { IDH1 }\end{array}$ & $\begin{array}{l}\text { SOX2, } \\
\text { FOXM1, FOXG1, } \\
\text { NANOG, STAT3, } \\
\text { GLI1, ASCLI, } \\
\text { ZFX, ZFHX4, } \\
\text { HOXA10, } \\
\text { EZH2/BMI1 }\end{array}$ & $\begin{array}{l}\text { NOTCH/integrin signaling } \\
\text { PI3K/Akt and MAPK signaling } \\
\text { TGF- } \beta \\
\text { Wnt/ } \beta \text {-catenin } \\
\text { Sonic hedgehog } \\
\text { VEGFR } \\
\text { L1CAM-integrin } \alpha 6 \\
\text { FACT } \\
\text { HIF } 2 \alpha\end{array}$ \\
\hline
\end{tabular}

Pediatric and adult brain cancer stem cells with the stem markers, gene, and epigenetic aberrations, as well as molecular drivers, are listed

MYCN = N-myc proto-oncogene; PI3K = phosphoinositide 3-kinase; $\mathrm{mTOR}=$ mechanistic target of rapamycin; TGF = transforming growth factor; VEGFR = vascular endothelial growth factor receptor; L1CAM = L1 cell adhesion molecule; FACT $=$ facilitates chromosome transcription; HIF = hypoxia-inducible factor

leads to the loss of electrons (ionization) in nucleic acids, proteins, and water. This results primarily in DNA damage and formation of toxic free radicals from water, leading to further damage. In response to radiation, GBM CSCs have been shown to possess enhanced DNA damage responses mediated primarily through the actions of poly adenosine diphosphate-ribose polymerase and ataxia telangiectasia mutated [34].

In addition to radiation, chemotherapeutics have been utilized based on their ability to modify or modulate DNA repair. Temozolomide (TMZ), a common oral chemotherapy drug, alkylates/methylates guanidine DNA residues thereby leading to cell death. The majority of tumor cells, and inclusively CSCs, have been shown to overexpress O-6-methylguanineDNA methyltransferase (MGMT), which removes the methylations introduced by TMZ thereby repairing damaged DNA [35]. Importantly, MGMT has been shown to mediate resistance to other alkylating agents such as nitrosoureas [36]. In addition to MGMT, deficiency in mismatch repair has been proposed as an additional mode of resistance in GBM cells; however, no studies have specifically evaluated this response in GBM CSCs. Augmented cell-cycle checkpoint response has also been observed in GBM CSCs through the activities of checkpoint kinases [33]. Through these various mechanisms, GBM CSCs are able to survive multiple insults.

The failure of effective clinical therapies has led to the exploration of a number of novel small molecule inhibitors of various pathways relevant in GBM CSCs; however, limited long-term benefit in the treatment of adult GBM has been reported. Currently, agents targeting diverse pathways, including phosphoinositide 3-kinase (PI3K) [37], wingless (WNT) [38], and NOTCH [39], in adult GBM CSCs are under clinical evaluation.

Aside from directly targeting tumor cells, altering the tumor microenvironment has been hypothesized as a therapeutic strategy. CSCs are not randomly distributed within a tumor but present in distinct anatomical niches, which contain nutrients, oxygen, and physical and soluble interactions that maintain CSC self-renewal. Multiple niches have been described in adult GBM, including the perivascular or proliferative niche, and the hypoxic or perinecrotic niche [40]. In addition, the relationship between CSCs and their niches is dynamic as CSCs may actively regulate niche formation and maintenance (Fig. 3).

Proximity to vascular endothelial cells has been shown to regulate directly CSC growth, with ablation of the vasculature leading to tumor regression. This has been shown to depend 
Fig. 3 Autocrine and paracrine loops

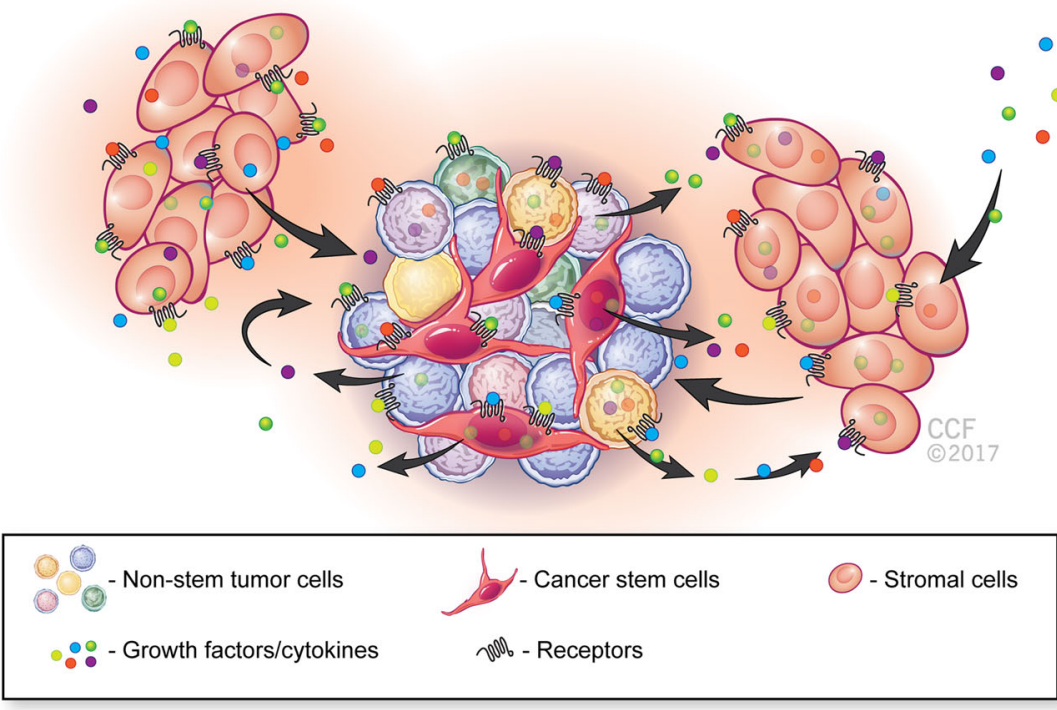

both on direct endothelial interaction $\mathrm{NOTCH}$ and integrin signaling) $[13,16,41]$, as well as paracrine signaling via soluble factors such as basic fibroblast growth factor, [42], nitric oxide [43] and sonic hedgehog (Shh) [44]. Extracellular matrix is another vital component of the perivascular niche. Direct interaction of laminins with CSC receptor integrin alpha 6 has been shown to be vital to proliferation and migration [16].

The hypoxic niche is not well defined structurally, characterized by low oxygen tension and increased acidity. This niche primarily regulates $\mathrm{CSC}$ behavior through the induction of transcription factors hypoxia-inducible factors $1 \alpha$ and $2 \alpha$ (HIF- $1 \alpha$ and HIF-2 $\alpha$, respectively) [45]. These transcription factors have been shown to regulate CSC proliferation and tumorigenicity [46], as will be described in detail below.

\section{Molecular Signatures of Brain CSCs}

Great efforts have been made in an attempt to understand the molecular signature of brain CSCs in both adult and pediatric populations, and much of this work has focused on adult GBM and childhood medulloblastoma models [47].

In adult GBM, CSCs have been reported to express various tumorigenic proteins that drive self-renewal, including (PI3K/Akt) and mitogen-activated protein kinase [48], transforming growth factor- $\beta$ (TGF- $\beta$ ) [49], the Wnt $\beta$ catenin pathway, and Shh signaling [50]; in vivo tumorigenicity such as L1CAM [51] and integrin alpha-6 [16]; angiogenic potential through upregulation of vascular endothelial growth factor (VEGF)/VEGF receptor [52]; and treatment resistance through Notch [39] and TGF- $\beta$ signaling pathways that have been shown to promote DNA repair. Furthermore, overexpression of the ABC-type transporters that efflux the drugs out of the GBM CSCs, has also been implicated in their drug-resistance [53]. In addition, the histone chaperone complex facilitates chromosome transcription (FACT) was recently reported to correlate with expression of CSC markers in an adult GBM model. FACT expression was found to correlate with gene transcription of stem markers SOX2, OCT4, OLIG2, and NANOG, and transcriptional knock-down of FACT or its inhibition with a small molecule (CBL0137) reduced the expression of these genes [54]. The overexpression of forkhead box protein M1 (FOXM1), a potent metastatic inducer and important regulator of NSPCs, was also found to be important for GBM CSCs. Interestingly, irradiation of GBM CSCs led to further upregulation of FOXM1, which rendered them radioresistant in a signal transducer and activator of transcription 3 (STAT3)-dependent manner [55]. STAT3 has also been described to be a key GBM CSC signaling node [56]. Finally, several other key oncogenic and stem-cell pathways have been implicated in adult GBM CSC maintenance, including c-MYC [57] and AEG-1, which facilitates $\beta$ catenin translocation to the nucleus and activates downstream targets of the Wnt pathway [58].

In the pediatric population, most studies have focused on medulloblastoma, which, along with other embryonal brain tumors, is believed to originate from NSPCs of the ventricular zone and cerebellar external germinal layer [59]. The notion that medulloblastoma contains "stem-like" features came about from the findings that pathways such as Wnt, Shh, and Notch, which govern NSPC specification, proliferation, and survival, are also aberrantly activated in such tumors, suggesting a molecular link between NSPCs and medulloblastoma [60-63]. It has been reported that $\mathrm{CD} 133^{+}$cells were reduced almost 5-fold after inhibiting Notch signaling in medulloblastoma cells and apoptotic rates following Notch blockade were almost 10 -fold higher in primitive nestinpositive cells compared with nestin ${ }^{-}$cells, thereby suggesting 
that these medulloblastoma stem cells exhibit a particular vulnerability to notch signaling inhibition [47]. In addition, MYCN has been reported to be involved in the survival and propagation of the aggressive medulloblastoma stem-like cells with CD133 expression, and thus targeting MYCN may be warranted [64].

Activation of the $\mathrm{PI} 3 \mathrm{~K} / \mathrm{Akt} / \mathrm{mech}$ anistic target of rapamycin (mTOR) pathway has also been reported in pediatric medulloblastoma nestin-expressing perivascular stem cells. It is believed that these CSCs are radiation resistant and are directly responsible for tumor recurrence via a p53dependent cell-cycle arrest and re-entry in to the cell cycle $72 \mathrm{~h}$ postradiotherapy [65]. Moreover, MYC amplification and p53 disruption in cerebellar stem cells have been shown to be associated with uncontrolled cell proliferation and aggressive tumor recurrence in an orthotopic model [66]. This finding implicates the possibility of transforming normal cerebellar stem cells into tumorigenic cells after MYC amplification and p53 disruption, suggesting that normal stem cells may become the "tumor-initiating" cells if primed with specific transforming mutations.

\section{Factors Influencing Brain CSCs}

\section{Microenvironmental Influences on Brain CSCs}

CSCs do not act alone but rather are part of an active microenvironment that drives tumor propagation (Fig. 3). Key properties of brain tumor CSC niches include elevated hypoxia and the interaction with infiltrating immune cell populations.

\section{Hypoxic Influences in Brain CSCs}

Hypoxia is associated with necrotic regions and increases the maintenance of GBM CSCs via a variety of mechanisms including HIF-1 $\alpha$ [67] and TGF- $\beta$ [68]. Hypoxic regions also contained elevated expression of CD133, alkaline phosphatase (another stem cell marker), and correlated with shorter overall, as well as progression-free, survival in adult patients with GBM [68]. HIF-1 $\alpha$ is a potent inducer of angiogenic factors leading to the aberrant vasculature and GBM progression. HIF-1 $\alpha$ was recently demonstrated to be activated independent of hypoxia via a profilin-1/von Hippel-Lindau interaction, the targeting of which exhibited reduced tumor angiogenesis, normal vasculature, and improved survival in a genetically engineered GBM mouse model [69]. Other hypoxia regulators have been demonstrated to be important in GBM CSCs, including von Hippel-Lindau, which interacts with inhibitor of DNA binding 2 protein increasing HIF- $2 \alpha$ levels [70]. Based on their importance in hypoxia and GBM CSC maintenance, identifying HIF-associated signaling nodes to target may reduce self-renewal. It was recently demonstrated that targeting HIF- $1 \alpha$ with digoxin resulted in increased survival in a GBM xenograft model. At the molecular level, digoxin decreased HIF- $1 \alpha$ protein expression, as well as the mRNA levels of VEGF and the CD34-positive vasculature within these tumors [71].

Hypoxic influences in pediatric brain CSCs have not been as extensively studied as in adults. One report showed that hypoxia inhibited p53 activation and subsequent astroglial differentiation of HGG precursors. The authors report that while HGG precursors generated endogenous bone morphogenetic protein (BMP) signaling leading to mitotic arrest under high oxygen tension, hypoxia actively repressed this signaling [72]. These results show a novel, mutually antagonistic interaction between hypoxia response and neural differentiation signals in HGG proliferation, and suggest differences between normal and HGG precursors, which may be exploited for pediatric brain cancer therapy. Furthermore, the expansion of medulloblastoma CSCs within the hypoxic niche has been observed, further implicating the role of hypoxia in inducing stem-like transformation of cells within pediatric brain tumors. These cells could be targeted via an oncolytic engineered herpes simplex virus strategy [73].

\section{Immune Evasion}

The ability of CSCs to evade the immune system may also be an important characteristic of specific cancer subtypes. The exact mechanisms that make brain CSCs predominantly non-antigenic remains unclear. Various reports have shown cancers to induce immune suppression mechanisms and deactivate key immune players such as inducing T-cell apoptosis or inhibiting their proliferation, activation of regulatory $\mathrm{T}$ (Treg) cells and deactivation of natural killer and dendritic cells $[74,75]$, in an attempt to evade the immune system.

The mechanisms by which CSCs evade immune surveillance include: 1) secretion of soluble factors such as arginase [76] and periostin [77], both of which recruit potent anti-inflammatory tumor-associated macrophages/microglia to suppress innate and adaptive immune responses; and 2) activation of cytotoxic T-cell apoptosis by secreting galectin-3 and enhancing Treg activity via TGF- $\beta$ and STAT3 activation. In addition, CSCs can suppress the function of immune cells by simply coming into direct contact with them via the cell surface expression of the programmed death-ligand $1[78]$.

It was recently reported that the CSC population within adult GBMs co-segregated with the immune-suppressive myeloid-derived suppressor cells, and that the CSCs were able to selectively drive myeloid-derived suppressor cells-mediated immune suppression via macrophage migration inhibitory factor [76]. Other reports have shown interleukin (IL)-6 to be highly overexpressed in the CSC population, rendering them immunosuppressive, and also enhanced the invasive 
potential of these cells, thus playing a prominent dual role in tumor immune evasion and invasion [79]. The therapeutic efficacy of the IL-12-expressing version of oncolytic engineered herpes simplex virus G47 (G47-mIL12) has been found to not only specifically kill CSC, but also inhibit Tregs and VEGF-induced neovascularization. leading to tumor regression [80]. Finally, the interaction between tumorassociated macrophages/microglia [81], TGF- $\beta$ [82], stressinducible protein 1 [83], and matrix metalloproteinases has been shown to intensify tumor invasion and infiltration by promoting extracellular matrix degradation.

There are limited studies investigating pediatric brain tumors and immune evasion. One report showed that indoleamine 2,3-dioxygenase 1 (IDO1) was overexpressed in pediatric medulloblastoma, and that cross-talk between mTOR and IDO1 induced immune escape in medulloblastoma cells [84]. Inhibition of mTOR potently induced IDO1 expression and activity, corroborating its ability to recruit Treg cells in the tumor microenvironment, which is the mechanism by which mTOR-targeted therapy fails. More recently, one report showed that central nervous system primitive neuroectodermal tumors are capable of evading immune recognition by downregulating the expression of their cell surface MHC-I and CD1d, and by overexpressing granzyme inhibitors SERPINB9, SERPINB1, and SERPINB4 [85]. Another study found that genetically downregulating Treg TGF- $\beta$ signaling nearly abolished Treg cells and inhibited medulloblastoma progression via $\mathrm{CD} 8^{+}$cytotoxic T-lymphocyte attack [86]. These findings suggest that medulloblastoma cells evade immune recognition possibly by upregulating TGF- $\beta$ signaling of Treg cells leading to the subsequent suppression of the immune responses and specifically T-cell-mediated immunity. Whether these immune-evasive mechanisms are the driving forces behind pediatric brain CSCs is yet to be established, and may be a potential platform to develop specific therapeutic targeting for pediatric brain tumors.

\section{Genetic and Epigenetic Influences in Brain CSCs}

Childhood brain tumors differ vastly from adult tumors in their genetic, epigenetic, and protein profiles (Fig. 4, Table 1). For instance, epigenetic regulation in pediatric brain tumors is more apparent than in adult tumors, whereas environmental and microenvironmental influences exert a greater impact on adult brain tumors. If a child develops a brain tumor before the age of 2 years, it is likely a result of genetic and/or epigenetic alterations that have induced tumorigenic transformation in certain cells within the developing brain, and not due to long-term carcinogen exposure that may be mutagenic in oncogenes or tumor suppressor genes [87]. Cancer arises from mutations in tumor promoters and tumor suppressors, and this mutational background also applies to CSCs.
A myriad of studies have shown that CSCs in adult brain tumors have genetic alterations affiliated with tumorigenesis, including amplifications or gain-of-function mutations in EGFR, PDGFRA, HDM2, PIK3CA, and PIK3R1; mutations or deletions of the tumor suppressors PTEN, TP53, CDKN2A, $N F 1, A T R X$, and RB1 [5, 88, 89]. Such mutations have rendered these tumor cells more malignant, immune evasive, therapeutically resistant, and recurrence prone. The only mutation found to correlate with a favorable prognosis is the isocitrate dehydrogenase 1 mutation, where long-term survival was evidenced in adult patients with GBM harboring such mutations, indicating that these tumors represent a unique class of less malignant GBM [90].

Genetic heterogeneity within single-cell clones has recently been investigated via patient-derived GBM cells. Some of these naïve patient-derived GBM clones expressed resistance to TMZ, indicating that conventional drug-resistance is inherent in these GBM clones. PTEN, EGFR, and the constitutively active EGFR deletion mutant, EGFRvIII were differentially expressed in three tumors, highlighting the variability of expression in distinct known molecular GBM drivers at the clonal level. This study also showed that multiple experiments conducted on clones of different passages, grown in identical culture conditions consistently exhibited diverse and independent variations in cellular proliferation and differentiation potential [91]. These findings further support the notion that targeting the bulk tumor mass in hopes of eradicating the tumor and achieving long-term, cancer-free survival is largely limited by this clonal heterogeneity.

Once again there has been little investigation into pediatric brain tumors for identifying specific genetic alterations that give rise to brain CSCs. Several groups are now studying the underlying genetic dysregulation in pediatric brain tumors, including $\mathrm{SHH}$, Wnt, and Notch signaling mutations in medulloblastomas [92], ERBB1 gene amplification and ACVR1, PDGFRA, and ATRX, $P P M I D$, and TP53 mutations in diffuse intrinsic pontine gliomas (DIPGs) [93], and $H 3 F 3 A$ and $D A X X$ mutations in childhood gliomas [94]. It is not yet known whether these or other genetic aberrations may be affiliated with a subset of CSCs within these tumors.

In a recent study that employed RCAS/TVA system to induce platelet-derived growth factor (PDGF)-B overexpression, $\mathrm{p} 53$ loss, and histone 3.3 lysine to methionine mutation (H3.3K27M) researchers were able to genetically engineer a model of pediatric DIPG upon exposure to ectopic PDGF-B ligand and p53-deficiency along with H3.3K27M overexpression [95]. This model could serve as a valuable tool to investigate experimentally the cell of origin and stem-cell perpetrator in pediatric HGGs. Further studies utilizing this model would shed light on some of the genetic alterations that may be the driving force of pediatric brain CSC propagation and maintenance. 
Fig. 4 Age-related tumor frequency. PDGFRA = platelet derived growth factor receptor A; ALT $=$ alanine transaminase; EGFR $=$ endothelial growth factor receptor; IDH1 = isocitrate dehydrogenase 1 ; TERT $=$ telomerase reverse transcriptase; $\mathrm{NF} 1=$ Neurofibromatosis type 1

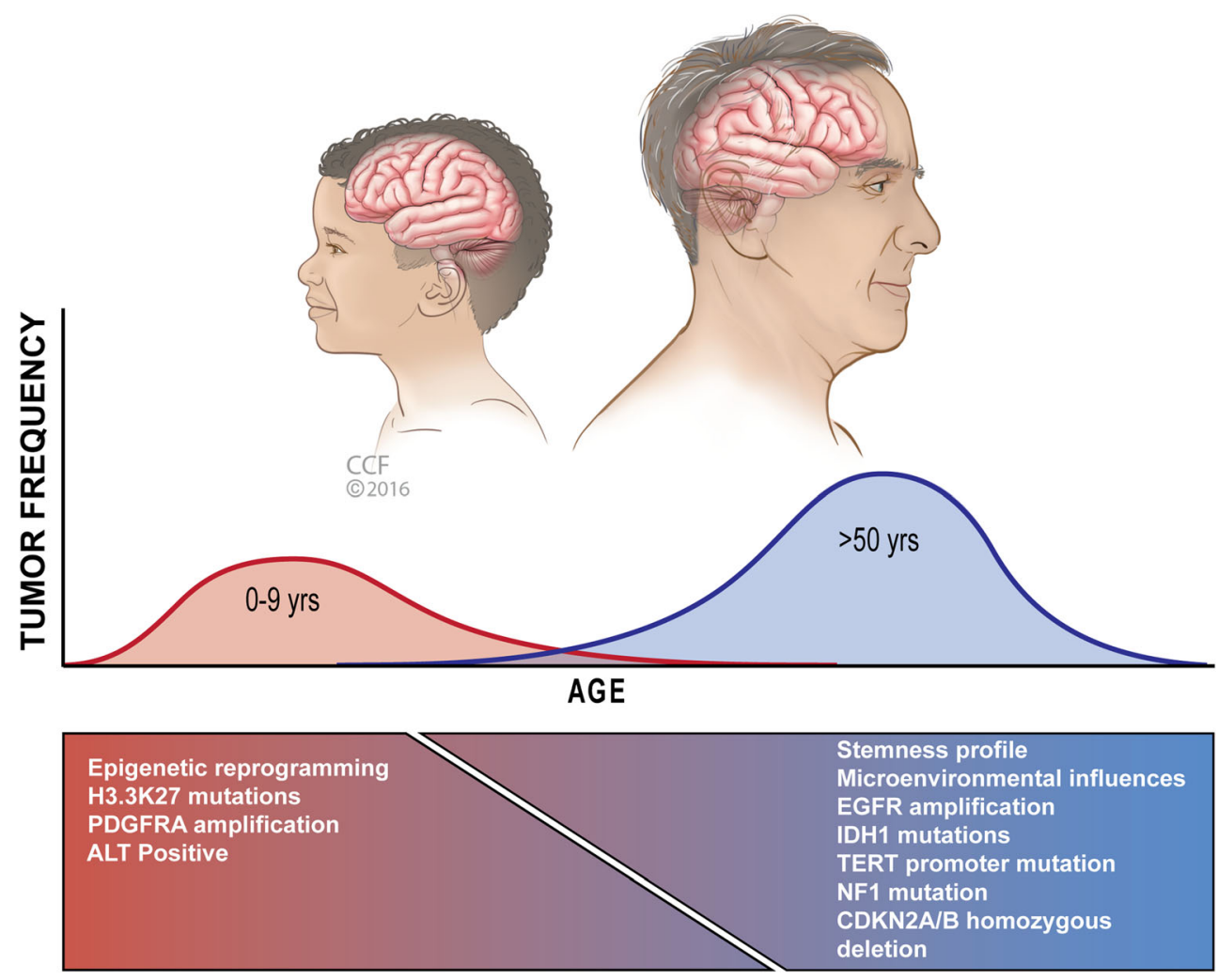

\section{Epigenetic Influences}

Epigenetic regulation, which refers to regulation of gene expression independent of genetic mutations, is now thought to be involved in pediatric and adult brain tumor CSCs. Cellular hierarchy in both normal [96] and neoplastic tissue is regulated by epigenetic mechanisms [25], including DNA methylation, chromatin remodeling through histone methylation, and regulatory noncoding RNAs [97]. This involves opening (mediated by methylation of $\mathrm{H} 3 \mathrm{~K} 4$ ) and closing (mediated by H3K27 methylation) of the chromatin, which is associated with gene activation and silencing, respectively.

Key chromatin modifiers such as mixed-lineage leukemia 1 have been demonstrated to be important in adult GBM CSCs via hypoxia-mediated HIF $2 \alpha$-induction [98] and activation of the homeobox gene HOXA10 [99]. The polycomb genes, EZH2 and BMI1, are believed to drive this transcriptional repression by histone methylation and reports have demonstrated that $E Z H 2$ silencing of the BMP pathway inhibits GBM CSC differentiation, and that self-renewal capacity and tumorigenicity is also lost with inhibition of EZH2 or forced expression of the BMP pathway in GSCs [100].

Other epigenetic regulators, including SOX2 [101], FOXM1 [102], FOXG1 [103], NANOG [104], STAT3 [105], GLI1 [44], ASCLI [106], ZFX [107], and ZFHX4 [108], have been reported to play crucial roles in the maintenance and self-renewal potential of adult GBM CSCs. Epigenetic silencing of glioblastoma genes involved in cell proliferation and cell-cell interaction (EMP3), angiogenesis (PCDH-gamma-A11), cell-cycle regulation (CDK2A-p16INK4a and CDK2B-p15INK4b), inhibition of apoptosis (DAPK1, TIMP3, CDH1), and drug resistance (O6MGMT) [109] underlines the importance of epigenetic profiling of various tumors, and further highlights the potential of targeting epigenetic regulators to reach more effective therapies.

Recent efforts have compared the epigenetic landscape of GBM CSCs and differentiated cells and identified a set of 4 transcription factors (POU3F2, SOX2, SALL2, and OLIG2) that are capable of inducing the differentiated GBM cells to undergo stem-like transformation into tumor-propagating cells in vivo [110]. This further highlight the dynamic plasticity that can be transcriptionally regulated within these malignant tumors, enabling their ability to transition between differentiated and undifferentiated states based on various external or internal challenges.

The epigenetic regulators that influence childhood malignancies have mainly been reported in DIPG. Recent studies found mutations in $H 3 F 3 A$ or HIST1H3B, which encode histone variant $\mathrm{H} 3.3$ or $\mathrm{H} 3.1$, respectively, resulting in the replacement of lysine residue at position 27 with methionine $(\mathrm{K} 27 \mathrm{M})$ or the glycine residue at position 34 with arginine or valine $(\mathrm{G} 34 \mathrm{R} / \mathrm{V})$ [111]. One group found that H3F3A K27M mutant GBMs show significant decreases in overall H3K27me3 without significant changes in EZH2 expression [112]. Furthermore, using human embryonic stem cells to 
model pediatric gliomas that harbor the $\mathrm{H} 3.3 \mathrm{~K} 27 \mathrm{M}$ histone mutation, it was observed that $\mathrm{H} 3.3 \mathrm{~K} 27 \mathrm{M}$ expression synergized with loss of the tumor suppressor $\mathrm{p} 53$ and activation of PDGFRA in NSPCs, which led to neoplastic transformation [113]. Another report found other mutations that target the receptor tyrosine kinase-RAS-PI3K signaling, and cellcycle regulation in $68 \%$ and $59 \%$ of pediatric DIPGs and the non-brainstem HGGs, respectively. In addition, the recurrent somatic mutation, ACVR1, which encodes for the bone BMP1, along with the frequent somatic mutations in histone H3 genes, TP53 and ATRX, have been reported in both DIPGs and non-brainstem HGGs [114]. Finally, by comparison $<3 \%$ of pediatric HGGs harbor the telomerase reverse transcriptase promoter mutations, while $86 \%$ occur in adult GBM [115]. This diversity between childhood and adult brain tumors as well as the intratumoral diversity emphasize the importance of devising targeted and personalized therapies.

Recent reports have found that polycomb transcription factor BMI1 to be highly correlated with Shh ligand concentrations in medulloblastoma CSCs, indicating that Shh signaling may play a pivotal role in BMI1 expression. Furthermore, it was determined that downstream effectors of BMI1 may be contributing to the activation of Shh, thus highlighting the importance of this reciprocal communication on the maintenance of medulloblastoma stem cell subpopulation [22]. In medulloblastoma groups 3 and 4 (both non-Shh/Wnt), BMII and FOXG1, genes known to be associated with self-renewal and proliferation [116], are overexpressed in CSCs. BMI1 has been very well characterized as a major epigenetic regulator of brain tumor CSC therapy resistance and self-renewal capacity in both adult and pediatric populations, and as such warrants further investigation as a potential therapeutic target in these cancers.

\section{Therapeutic Challenges in Brain CSCs}

Malignant brain tumors remain a challenge to treat for a variety of factors, including the interdependence of microenvironmental, genetic, and epigenetic factors that drive the CSC state, as discussed above. While a number of new smallmolecule inhibitors of receptor tyrosine kinases, antiangiogenic factors, antiproliferative, and proapoptotic agents such as PDGFR $\alpha / \beta$, VEGFR, EGFR, PI3K, and mTOR [117] are being evaluated in adult GBM, these have not resulted in significant improvements in the progression-free or overall survival rates. The same can be said for studies that have explored the use of combination therapies that use chemotherapeutic agents and/or radiotherapy along with inhibitors of receptor tyrosine kinases, histone deacetylases, mTOR, DNA topoisomerases, integrins, or immune modulators. These failures may be due, in part, to the inability to effectively target CSCs.

CSC-targeting strategies have shown some promise as a recent study has reported a 2.9-fold increase in progressionfree survival with a vaccine strategy using autologous CSCs with mRNA-transfected dendritic cells in patients with GBM [118]. Studies such as these suggest that CSC targeting strategies may be more effective than conventional therapies and thus warrants larger-scale investigation. However, future studies are likely to benefit from additional considerations that drive therapeutic failure, including redundant signaling of overlapping pathways involved in CSC growth/survival mechanisms. Moreover, fluid transport and retention mechanisms both at the brain-vascular (i.e., blood-brain barrier) and cellular membrane level (i.e., drug-efflux protein pumps) may also contribute, in part, to drug-resistance in brain tumors. Brain tumor
Fig. 5 Resistance to cytotoxic DNA damaging agents

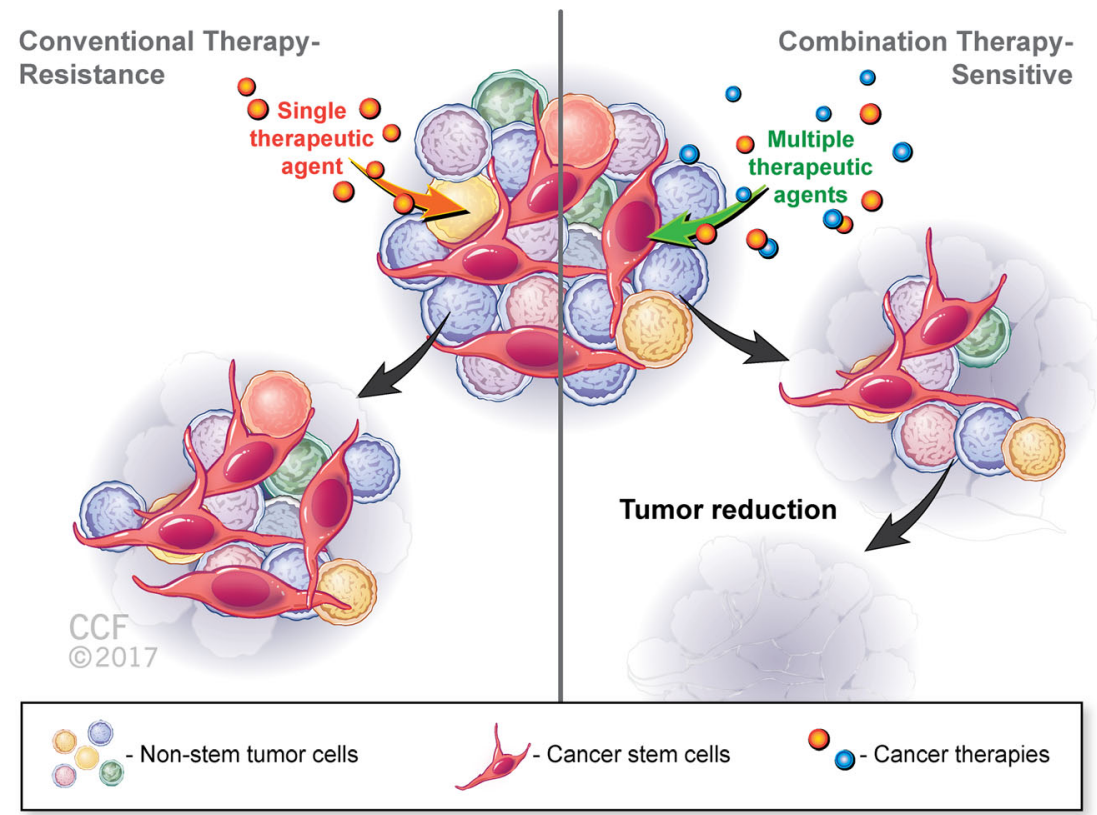


CSCs specifically are thought to be drug resistant owing to upregulation of proteins involved in active drug efflux [119], thus sparing CSCs from cytotoxicity and apoptosis. Other factors such as hypoxic areas of tumor cells [46], direct cell-cell communication, local secretion of the cytokines IL-6 or stromal cell-derived factor 1, DNA damage repair [33], and microRNAs [120] are also reasons of drug resistance in GBM. Another major consideration is the inherent plasticity of CSCs, transitioning between stem and differentiated cell states, as well as the rise of new CSCs from the differentiated population, places additional challenges in developing effective therapies (Fig. 2). Multimodality approaches that target growth factors, tumorigenic pathways, epigenetic, and microenvironmental factors that are responsible for CSC plasticity should be considered. These considerations are relevant for both adult and pediatric tumors and leveraging the epigenetic state may be especially effective in the pediatric setting as these tumors rely on epigenetic regulation and cannot be as aggressively treated with surgery, radiation, and chemotherapy as in adult brain tumors.

\section{Implications for Future Developments in Brain CSC Therapeutics}

As a challenge to treat tumors effectively involves therapeutic resistance via the integration of microenvironmental, genetic, and epigenetic factors that converge on the stem-cell state, the development of CSC targeting strategies remains a priority for future efforts. Considerations for therapeutic development should include neutralizing the stem-cell phenotype, selfrenewal pathways, and transitions into the stem cell state. These therapies may take several forms, including smallmolecule inhibitors, natural products and/or diet modification, or viral delivery, but each strategy should take into consideration the blood-brain barrier and achieving effective tumor penetrance.

Embedded within the stem cell phenotype is the ability to self-renew and resist therapies via resistance to redox stress, efficient DNA repair capacity, metabolic reprogramming, ability to withstand hyponutritious and hyperinflammatory conditions, and the ability to expel anticancer drugs by upregulation of $\mathrm{ABC}$ drug efflux transporters (Fig. 5). Confounding targeting efforts is the relatively quiescent nature to some CSC populations, which provides an additional challenge to target if the strategy is predicated on proliferation to generate an effect. An emerging consideration is the interaction between $\mathrm{CSCs}$ and the immune system. Immuno-oncology efforts for treating brain tumors would benefit from the integration of CSCs into their models as there may be an opportunity to generate a more sustained immune response by concomitant targeting of CSCs.
Another consideration is specific self-renewal pathway targeting, which is currently being explored in a variety of tumors. Such pathways that may be considered include Wnt/ $\beta$-catenin [121], Notch [122], SHH [123], EGFR, and STAT3. It will be important to assess how targeting these pathways impacts other neural cell types, including NSPCs, as well as potential resistance mechanisms that may emerge.

As discussed above, the stem-cell state can be induced via stress present in the microenvironment, including hypoxia, lower $\mathrm{pH}$, or metabolic stress. The advances that have been made to identify molecular mechanisms that drive the stemcell state could be leverage for therapeutic development. Successful strategies may prevent the cellular stress response and not only target the stem cell state, but also sensitize cells to these stresses.

\section{Conclusions/Summary}

Current available treatments have been shown to slow progression, but most often fail to eradicate brain tumors. It is likely that these treatments effectively kill many tumor cells but do not effectively target the highly malignant CSCs that adapt rapidly to give rise to recurrent, treatment-resistant malignancies. Our evolving understanding of the genetic, epigenetic, and molecular signatures and microenvironmental influences that may be unique to CSCs will enable us to develop more effective multimodal therapies for a variety of distinct tumor subtypes based on these characterizations. These targeted therapies may likely be different between pediatric and adult patients with brain tumors based on the genetic, epigenetic, molecular signatures, and microenvironmental influences that drive these cancers.

Required Author Forms Disclosure forms provided by the authors are available with the online version of this article.

\section{References}

1. Ostrom QT, Gittleman H, de Blank PM et al. American Brain Tumor Association. Adolescent and young adult primary brain and central nervous system tumors diagnosed in the United States in 2008-2012. Neuro Oncol 2016; Suppl 1:i1-i50.

2. Vigneswaran K, Neill S, Hadjipanayis CG. Beyond the World Health Organization grading of infiltrating gliomas: advances in the molecular genetics of glioma classification. Ann Transl Med 2015;3:95.

3. Jelsma R, Bucy PC. The treatment of glioblastoma multiforme of the brain. J Neurosurg 1967;27(5):388-400.

4. Weller M, Cloughesy T, Perry JR, Wick W. Standards of care for treatment of recurrent glioblastoma - are we there yet? Neuro Oncol 2013;15:4-27.

5. Lathia JD, Mack SC, Mulkearns-Hubert EE, Valentim CLL, Rich JN. Cancer stem cells in glioblastoma. Genes Develop 2015;29: 1203-1217. 
6. Cavallucci V, Fidaleo M, Pani G. Neural stem cells and nutrients: poised between quiescence and exhaustion. Trends Endocrinol Metab 2016; 27:756-769.

7. Rusznák Z, Henskens W, Schofield E, Kim WS, Fu Y. Adult neurogenesis and gliogenesis: possible mechanisms for neurorestoration. Exp Neurobiol 2016;25:103-112.

8. Hale JS, Sinyuk M, Rich JN, Lathia JD. Decoding the cancer stem cell hypothesis in glioblastoma. CNS Oncol 2013;2:10.2217/cns. 13.23.

9. Reynolds BA, Weiss S. Clonal and population analyses demonstrate that an EGF-responsive mammalian embryonic CNS precursor is a stem cell. Dev Biol 1996;175(1):1-13.

10. Al-Hajj M, Wicha MS, Benito-Hernandez A, Morrison SJ, Clarke MF. Prospective identification of tumorigenic breast cancer cells. Proc Natl Acad Sci U S A 2003;100:3983-3988.

11. Ricci-Vitiani L, Lombardi DG, Pilozzi E et al. Identification and expansion of human colon-cancer-initiating cells. Nature 2007;445:111-115.

12. Ignatova TN, Kukekov VG, Laywell ED, Suslov ON, Vrionis FD, Steindler DA. Human cortical glial tumors contain neural stemlike cells expressing astroglial and neuronal markers in vitro. Glia 2002;39(3):193-206

13. Bapat SA, Mali AM, Koppikar CB, Kurrey NK. Stem and progenitor-like cells contribute to the aggressive behavior of human epithelial ovarian cancer. Cancer Res 2005;65:3025-3029.

14. Lathia JD. Cancer stem cells: moving past the controversy. CNS Oncol 2013;2(6):465-467.

15. Hemmati HD, Nakano I, Lazareff JA, et al. Cancerous stem cells can arise from pediatric brain tumors. Proc Natl Acad Sci U S A 2003; 100:15178-15183.

16. Lathia JD, Gallagher J, Heddleston JM, et al. Integrin alpha 6 regulates glioblastoma stem cells. Cell Stem Cell 2010;6:421-432.

17. Hale JS, Otvos B, Sinyuk M, et al. Cancer stem cell-specific scavenger receptor CD36 drives glioblastoma progression. Stem Cells 2014;32:1746-1758.

18. Ogden AT, Waziri AE, Lochhead RA et al. Identification of A2B5+CD133- tumor-initiating cells in adult human gliomas. Neurosurgery 2008;62:505-514.

19. Liu G, Yuan X, Zeng Z, et al. Analysis of gene expression and chemoresistance of $\mathrm{CD} 133^{+}$cancer stem cells in glioblastoma. Mol Cancer 2006;5:67.

20. Bao S, Wu Q, Li Z, et al. Targeting Cancer Stem Cells through L1CAM Suppresses glioma growth. Cancer Res 2008;68:60436048.

21. Mazzoleni S, Politi LS, Pala M, et al. Epidermal growth factor receptor expression identifies functionally and molecularly distinct tumor-initiating cells in human glioblastoma multiforme and is required for gliomagenesis. Cancer Res 2010;70:75007513.

22. Wang X, Venugopal C, Manoranjan B, et al. Sonic hedgehog regulates Bmil in human medulloblastoma brain tumor-initiating cells. Oncogene 2012;31:187-199.

23. Ligon KL, Huillard E, Mehta S, et al. Olig2-regulated lineagerestricted pathway controls replication competence in neural stem cells and malignant glioma. Neuron 2007;53:503-517.

24. Berezovsky AD, Poisson LM, Cherba D, et al. Sox2 promotes malignancy in glioblastoma by regulating plasticity and astrocytic differentiation. Neoplasia 2014;16:193-206.

25. Carén H, Pollard SM, Beck S. The good, the bad and the ugly: epigenetic mechanisms in glioblastoma. Mol Aspects Med 2013;34:849-862.

26. Brian J. P. Huntly and D. Gary Gilliland. Leukaemia stem cells and the evolution of cancer-stem-cell research. Nat Rev Cancer $2005 ; 5: 311-321$.
27. Bonnet D, Dick JE. Human acute myeloid leukemia is organized as a hierarchy that originates from a primitive hematopoietic cell. Nat Med 1997; 3:730-737.

28. Singh SK, Clarke ID, Terasaki M et al. Identification of a cancer stem cell in human brain tumors. Cancer Res 2003; 63: 58215828 .

29. Singh SK, Clarke ID, Hide T, Dirks PB. Cancer stem cells in nervous system tumors. Oncogene 2004; 23: 7267-7273.

30. Read T-A, Fogarty MP, Markant SL, et al. Identification of CD15 as a marker for tumor-propagating cells in a mouse model of medulloblastoma. Cancer Cell 2009;15:135-147.

31. Vanner RJ, Remke M, Gallo M, et al. Quiescent Sox $2^{+}$cells drive hierarchical growth and relapse in sonic hedgehog subgroup medulloblastoma. Cancer Cell 2014; 26: 33-47.

32. Chen J, Li Y, Yu T-S, et al. A restricted cell population propagates glioblastoma growth following chemotherapy. Nature 2012;488: 522-526.

33. Bao $\mathrm{S}, \mathrm{Wu} \mathrm{Q}, \mathrm{McLendon} \mathrm{RE}$, et al. Glioma stem cells promote radioresistance by preferential activation of the DNA damage response. Nature 2006;444:756-760.

34. Carruthers R, Ahmed SU, Strathdee K. et al. Abrogation of radioresistance in glioblastoma stem-like cells by inhibition of ATM kinase. Mol Oncol 2015;9:192-203.

35. Beier D, Röhrl S, Pillai DR. et al. Temozolomide preferentially depletes cancer stem cells in glioblastoma. Cancer Res 2008;68: 5706-5715.

36. Passagne I, Evrard A, Depeille P, Cuq P, Cupissol D, Vian L. O(6)methylguanine DNA-methyltransferase (MGMT) overexpression in melanoma cells induces resistance to nitrosoureas and temozolomide but sensitizes to mitomycin C. Toxicol Appl Pharmacol 2006;211:97-105

37. Firat E, Niedermann G. FoxO proteins or loss of functional p53 maintain stemness of glioblastoma stem cells and survival after ionizing radiation plus PI3K/mTOR inhibition. Oncotarget 2016; 7: 54883-54896.

38. Duan R, Han L, Wang Q, et al. HOXA13 is a potential GBM diagnostic marker and promotes glioma invasion by activating the Wnt and TGF- $\beta$ pathways. Oncotarget 2015;6:27778-27793.

39. Yahyanejad S, King H, Iglesias VS et al. NOTCH blockade combined with radiation therapy and temozolomide prolongs survival of orthotopic glioblastoma. Oncotarget 2016;7:41251-41264.

40. Codrici E, Enciu AM, Popescu ID, Mihai S, Tanase C. Glioma stem cells and their microenvironments: providers of challenging therapeutic targets. Stem Cells Int 2016; 5728438.

41. Zhu TS, Costello MA, Talsma CE, et al. Endothelial cells create a stem cell niche in glioblastoma by providing Notch ligands that nurture self-renewal of cancer stem-like cells. Cancer Res 2011;71:6061-6072.

42. Fessler E, Borovski T, Medema JP. Endothelial cells induce cancer stem cell features in differentiated glioblastoma cells via bFGF. Mol Cancer 2015;14:157.

43. Charles N, Ozawa T, Squatrito M, et al. Perivascular nitric oxide activates Notch signaling and promotes stem-like character in PDGF-induced glioma cells. Cell Stem Cell 2010;6.

44. Clement V, Sanchez P, de Tribolet N, Radovanovic I, Ruiz i Altaba A. HEDGEHOG-GLI1 signaling regulates human glioma growth, cancer stem cell self-renewal, and tumorigenicity. Curr Biol 2007; 17:165-172.

45. Yang L, Lin C, Wang L, Guo H, Wang X. Hypoxia and hypoxiainducible factors in glioblastoma multiforme progression and therapeutic implications. Exp Cell Res 2012;318:2417-2426.

46. $\mathrm{Li} \mathrm{Z}, \mathrm{Bao} \mathrm{S}, \mathrm{Wu} \mathrm{Q}$, et al. Hypoxia-inducible factors regulate tumorigenic capacity of glioma stem cells. Cancer Cell 2009;15: 501-513. 
47. Xing Fan, William Matsui, Leila Khaki, et al. Notch pathway inhibition depletes stem-like cells and blocks engraftment in embryonal brain tumors. Cancer Res 2006;66:7445-7452.

48. Lee J, Kotliarova S, Kotliarov $\mathrm{Y}$ et al. Tumor stem cells derived from glioblastomas cultured in bFGF and EGF more closely mirror the phenotype and genotype of primary tumors than do serumcultured cell lines. Cancer Cell 2006;9:391-403.

49. Ghosh D, Ulasov IV, Chen L. et al. TGF $\beta$-responsive HMOX1 expression is associated with stemness and invasion in glioblastoma multiforme. Stem Cells 2016;34:2276-2289.

50. Jin $X$, Jeon HM, Jin $X$ et al. The ID1-CULLIN3 axis regulates intracellular SHH and WNT signaling in glioblastoma stem cells. Cell Rep 2016;16:1629-1641.

51. Cheng L, Wu Q, Guryanova OA, et al. Elevated invasive potential of glioblastoma stem cells. Biochem Biophys Res Commun 2011;406:643-648.

52. Bao $\mathrm{S}, \mathrm{Wu} \mathrm{Q}$, Sathornsumetee $\mathrm{S}$. et al. Stem cell-like glioma cells promote tumor angiogenesis through vascular endothelial growth factor. Cancer Res 2006;66:7843-7848.

53. Xi G, Hayes E, Lewis R, et al. CD133 and DNA-PK regulate MDR1 via the PI3K- or Akt-NF-KB pathway in multidrugresistant glioblastoma cells in vitro. Oncogene 2016;35:241-250.

54. Dermawan JK, Hitomi M, Silver DJ, et al. Pharmacological targeting of the histone chaperone complex FACT preferentially eliminates glioblastoma stem cells and prolongs survival in preclinical models. Cancer Res 2016;76:2432-2442.

55. Maachani UB, Shankavaram U, Kramp T, Tofilon PJ, Camphausen K, Tandle AT. FOXM1 and STAT3 interaction confers radioresistance in glioblastoma cells. Oncotarget 2016;7: $77365-77377$.

56. Liu M, Inoue K, Leng T, Guo S, Xiong Z. TRPM7 channels regulate glioma stem cell through STAT3 and Notch signaling pathways. Cell Signal 2014;26:2773-2781.

57. Fang X, Zhou W, Wu Q, et al. Deubiquitinase USP13 maintains glioblastoma stem cells by antagonizing FBXL14-mediated Myc ubiquitination. J Exp Med 2017;214:245-267.

58. Hu B, Emdad L, Kegelman TP, et al. Astrocyte elevated gene-1 regulates beta-catenin signaling to maintain glioma stem-like stemness and self-renewal. Mol Cancer Res 2017;15:225-233.

59. Oliver TG, Wechsler-Reya RJ. Getting at the root and stem of brain tumors. Neuron 2004; 42: 885-888.

60. Raffel C, Jenkins RB, Frederick L, et al. Sporadic medulloblastomas contain PTCH mutations. Cancer Res 1997; 57: 842-845.

61. Reifenberger J, Wolter M, Weber RG, et al. Missense mutations in $\mathrm{SMOH}$ in sporadic basal cell carcinomas of the skin and primitive neuroectodermal tumors of the central nervous system. Cancer Res 1998; 58: 1798-1803.

62. Zurawel RH, Chiappa SA, Allen C, Raffel C. Sporadic medulloblastomas contain oncogenic $\beta$-catenin mutations. Cancer Res 1998; 58: 896-899.

63. Hallahan AR, Pritchard JI, Hansen S, et al. The SmoA1 mouse model reveals that notch signaling is critical for the growth and survival of sonic hedgehog-induced medulloblastomas. Cancer Res 2004; 64: 7794-7800.

64. Ahmad Z, Jasnos L, Gil V, et al. Molecular and in vivo characterization of cancer-propagating cells derived from MYCNdependent medulloblastoma. PLOS ONE 2015;10(3):e0119834.

65. Dolores Hambardzumyan, Oren J. Becher, et al. PI3K pathway regulates survival of cancer stem cells residing in the perivascular niche following radiation in medulloblastoma in vivo. Genes Dev 2008;22:436-448.

66. Pei Y, Moore CE, Wang J, et al. An animal model of Myc-driven medduloblastoma. Cancer Cell 2012; 21: 155-167.

67. Mineo M, Ricklefs F, Rooj AK, et al. The Long Non-coding RNA HIF1A-AS2 facilitates the maintenance of mesenchymal glioblastoma stem-like cells in hypoxic niches. Cell Rep 2016; 15:2500-2509.

68. Iwadate Y, Matsutani T, Hirono S, Shinozaki N, Saeki N. Transforming growth factor- $\beta$ and stem cell markers are highly expressed around necrotic areas in glioblastoma. J Neurooncol 2016;129:101-107.

69. Fan Y, Potdar AA, Gong Y, et al. Profilin-1 phosphorylation directs angiocrine expression and glioblastoma progression through HIF-1 $\alpha$ accumulation. Nat Cell Biol 2014;16:445-456.

70. Lee SB, Frattin V, Bansal M, et al. An ID2-dependent mechanism for VHL inactivation in cancer. Nature 2016;529:172-177.

71. Nigim F, Cavanaugh J, Patel AP, et al. targeting hypoxia-inducible factor $1 \alpha$ in a new orthotopic model of glioblastoma recapitulating the hypoxic tumor microenvironment. J Neuropathol Exp Neurol 2015;74:710-722.

72. Pistollato F, Chen HL, Rood BR, et al. Hypoxia and HIF1alpha repress the differentiative effects of BMPs in high-grade glioma. Stem Cells 2009;27:7-17.

73. Friedman GK, Moore BP, Nan L, et al. Pediatric medulloblastoma xenografts including molecular subgroup 3 and CD133+ and CD15+ cells are sensitive to killing by oncolytic herpes simplex viruses. Neuro Oncol 2016;18:227-235.

74. Huettner C, Czub S, Kerkau S, Roggendorf W, Tonn JC. Interleukin 10 is expressed in human gliomas in vivo and increases glioma cell proliferation and motility in vitro. Anticancer Res 1997; 17:3217-3224.

75. Jackson C, Ruzevick J, Phallen J, Belcaid Z, Lim M. Challenges in immunotherapy presented by the glioblastoma multiforme microenvironment. Clin Dev Immunol 2011;732413.

76. Otvos B, Silver DJ, Mulkearns-Hubert EE, et al. Cancer stem cellsecreted macrophage migration inhibitory factor stimulates myeloid derived suppressor cell function and facilitates glioblastoma immune evasion. Stem Cells 2016; 34: 2026-2039.

77. Zhou W, Ke SQ, Huang Z, et al. Periostin secreted by glioblastoma stem cells recruits $\mathrm{M} 2$ tumor-associated macrophages and promotes malignant growth. Nat Cell Biol 2015;17:170-182.

78. Silver DJ, Sinyuk M, Vogelbaum MA, Ahluwalia MS, Lathia JD. The intersection of cancer, cancer stem cells, and the immune system: therapeutic opportunities. Neuro Oncol 2016; 18: 153159.

79. Qiu B, Zhang D, Wang Y, et al. Interleukin-6 is overexpressed and augments invasiveness of human glioma stem cells in vitro. Clin Exp Metastasis 2013;30:1009-1018.

80. Cheema TA, Fecci PE, Ning J, Rabkin SD. Immunovirotherapy for the treatment of glioblastoma. Oncoimmunology 2014;3: e27218.

81. Markovic DS, Vinnakota K, Chirasani S, et al. Gliomas induce and exploit microglial MT1-MMP expression for tumor expansion. Proc Natl Acad Sci U S A 2009;106:12530-12535.

82. Ye XZ, Xu SL, Xin YH, et al. Tumor-associated microglia/ macrophages enhance the invasion of glioma stem-like cells via TGF-beta1 signaling pathway. J Immunol 2012;189:444-453.

83. Fonseca AC, Romao L, Amaral RF, et al. Microglial stress inducible protein 1 promotes proliferation and migration in human glioblastoma cells. Neuroscience 2012;200:130-141.

84. Folgiero V, Miele E, Carai A, et al. IDO1 involvement in mTOR pathway: A molecular mechanism of resistance to mTOR targeting in medulloblastoma. Oncotarget 2016; 7: 52900-52911.

85. Vermeulen JF, van Hecke W, Spliet WG, et al. Pediatric primitive neuroectodermal tumors of the central nervous system differentially express granzyme inhibitors. PLOS ONE 2016;11: e0151465.

86. Gate D, Danielpour M, Rodriguez J Jr, et al. T-cell TGF- $\beta$ signaling abrogation restricts medulloblastoma progression. Proc Natl Acad Sci U S A 2014;111:E3458-E3466. 
87. Kunkle B, Yoo C, Roy D. Discovering gene-environment interactions in glioblastoma through a comprehensive data integration bioinformatics method. Neurotoxicology 2013;35:1-14.

88. Parsons DW, Jones S, Zhang X, et al. An integrated genomic analysis of human glioblastoma multiforme. Science 2008;321: 1807-1812.

89. Cancer Genome Atlas Research Network. Comprehensive genomic characterization defines human glioblastoma genes and core pathways. Nature 2008;455:1061-1068.

90. Weller M, Pfister SM, Wick W, Hegi ME, Reifenberger G, Stupp R. Molecular neuro-oncology in clinical practice: a new horizon. Lancet Oncol 2013;14: e370-e379.

91. Meyera M, Reimandb J, Lan X, et al. Single cell-derived clonal analysis of human glioblastoma links functional and genomic heterogeneity. PNAS 2015;112: 851-856.

92. Remke M, Ramaswamy V, Taylor MD. Medulloblastoma molecular dissection: the way toward targeted therapy. Curr Opin Oncol 2013;25:674-681.

93. Jones C, Baker SJ. Unique genetic and epigenetic mechanisms driving paediatric diffuse high-grade glioma. Nat Rev Cancer 2014;14:10.

94. Appin CL, Brat DJ. Molecular genetics of gliomas. Cancer J 2014;20:66-72.

95. Misuraca KL, Hu G, Barton KL, Chung A, Becher OJ. A Novel mouse model of diffuse intrinsic pontine glioma initiated in Pax3expressing cells. Neoplasia 2016;18:60-70.

96. Smith ZD, Meissner A. DNA methylation: roles in mammalian development. Nat Rev Genet 2013;14:204-220.

97. Heddleston JM, Hitomi M, Venere M, et al. Glioma stem cell maintenance: the role of the microenvironment. Curr Pharm Des 2011;17:2386-2401.

98. Heddleston JM, Wu Q, Rivera M, et al. Hypoxia-induced mixedlineage leukemia 1 regulates glioma stem cell tumorigenic potential. Cell Death Differ 2012;19:428-439.

99. Gallo M, Ho J, Coutinho FJ, et al. A tumorigenic MLL-homeobox network in human glioblastoma stem cells. Cancer Res 2013;73: 417-427.

100. Lee J, Son MJ, Woolard K, et al. Epigenetic-mediated dysfunction of the bone morphogenetic protein pathway inhibits differentiation of glioblastoma-initiating cells. Cancer Cell 2008;13:69-80.

101. Gangemi RM, Griffero F, Marubbi D, et al. SOX2 silencing in glioblastoma tumor-initiating cells causes stop of proliferation and loss of tumorigenicity. Stem Cells 2009;27:40-48.

102. Joshi K, Banasavadi-Siddegowda Y, Mo X, et al. MELKdependent FOXM1 phosphorylation is essential for proliferation of glioma stem cells. Stem Cells 2013;31:1051-1063.

103. Verginelli F, Perin A, Dali R, et al. Transcription factors FOXG1 and Groucho/TLE promote glioblastoma growth. Nat Commun 2013;4:2956.

104. Zbinden M, Duquet A, Lorente-Trigos A, Ngwabyt SN, Borges I, Ruiz i Altaba A. NANOG regulates glioma stem cells and is essential in vivo acting in a cross-functional network with GLI1 and p53. EMBO J 2010;29:2659-2674.

105. Sherry MM, Reeves A, Wu JK, Cochran BH. STAT3 is required for proliferation and maintenance of multipotency in glioblastoma stem cells. Stem Cells 2009;10:2383-2392.

106. Rheinbay E, Suva ML, Gillespie SM, et al. An aberrant transcription factor network essential for Wnt signaling and stem cell maintenance in glioblastoma. Cell Rep 2013;3:1567-1579.
107. Fang X, Huang Z, Zhou W, et al. The zinc finger transcription factor ZFX is required for maintaining the tumorigenic potential of glioblastoma stem cells. Stem Cells 2014;32:2033-2047.

108. Chudnovsky Y, Kim D, Zheng S, et al. ZFHX4 interacts with the $\mathrm{NuRD}$ core member CHD4 and regulates the glioblastoma tumorinitiating cell state. Cell Rep 2014;6:313-324.

109. Liu A, Hou C, Chen H, Zong X, Zong P. Genetics and epigenetics of glioblastoma: applications and overall incidence of IDH1 mutation. Front Oncol 2016;6:16.

110. Suvà ML, Rheinbay E, Gillespie SM, et al. Reconstructing and reprogramming the tumor-propagating potential of glioblastoma stem-like cells. Cell 2014;157:580-594.

111. Wu G, Broniscer A, McEachron TA, et al.; St. Jude Children's Research Hospital-Washington University Pediatric Cancer Genome Project. Somatic histone H3 alterations in pediatric diffuse intrinsic pontine gliomas and non-brainstem glioblastomas. Nat Genet 2012;44:251-253.

112. Venneti S, Garimella MT, Sullivan LM, et al. Evaluation of histone 3 lysine 27 trimethylation (H3K27me3) and enhancer of Zest 2 (EZH2) in pediatric glial and glioneuronal tumors shows decreased H3K27me3 in H3F3A K27M mutant glioblastomas. Brain Pathol 2013;23:558-564.

113. Funato K, Major T, Lewis PW, Allis CD, Tabar V. Use of human embryonic stem cells to model pediatric gliomas with H3.3K27M histone mutation. Science 2014;346:1529-1533.

114. Wu G, Diaz AK, Paugh BS, et al. St. Jude Children's Research Hospital-Washington University Pediatric Cancer Genome Project. The genomic landscape of diffuse intrinsic pontine glioma and pediatric non-brainstem high-grade glioma. Nat Genet 2014;46:444-450.

115. Killela PJ, Reitman ZJ, Jiao Y, et al. TERT promoter mutations occur frequently in gliomas and a subset of tumors derived from cells with low rates of self-renewal. Proc Natl Acad Sci U S A 2013;110:6021-6026.

116. Manoranjan B, Wang X, Hallett RM, et al. FoxG1 interacts with Bmil to regulate self-renewal and tumorigenicity of medulloblastoma stem cells. Stem Cells 2013;31:1266-1277.

117. Takeuchi K, Ito F. Receptor tyrosine kinases and targeted cancer therapeutics. Biol Pharm Bull 2011;34:1774-1780.

118. Vik-Mo EO, Nyakas M, Mikkelsen BV, et al. Therapeutic vaccination against autologous cancer stem cells with mRNAtransfected dendritic cells in patients with glioblastoma. Cancer Immunol Immunother 2013;62:1499-1509.

119. Hirschmann-Jax C, Foster AE, Wulf GG, et al. A distinct "side population" of cells with high drug efflux capacity in human tumor cells. Proc Natl Acad Sci U S A 2004;101:14228-14233.

120. Costa PM, Cardoso AL, Custódia C, et al. MiRNA-21 silencing mediated by tumor-targeted nanoparticles combined with sunitinib: a new multimodal gene therapy approach for glioblastoma. J Control Release 2015;207:31-39.

121. Venugopal C, Hallett R, Vora P, et al. Pyrvinium targets CD133 in human glioblastoma brain tumor-initiating cells. Clin Cancer Res 2015;21:5324-5337.

122. Fouladi M, Stewart CF, Olson J, et al. Phase I trial of MK-0752 in children with refractory CNS malignancies: a Pediatric Brain Tumor Consortium study. J Clin Oncol 2011;29:3529-3534.

123. Robinson GW, Orr BA, Wu G, et al. Vismodegib exerts targeted efficacy against recurrent sonic hedgehog-subgroup medulloblastoma: results from phase II pediatric brain tumor consortium studies PBTC-025B and PBTC032. J Clin Oncol 2015;33:2646-2654. 